\title{
In vitro and in vivo biological activities of azulene derivatives with potential applications in medicine
}

\author{
Paweł Bakun ${ }^{1} \cdot$ Beata Czarczynska-Goslinska² ${ }^{2}$ Tomasz Goslinski $\mathbb{1}^{1} \cdot$ Sebastian Lijewski ${ }^{1}$
}

Received: 19 November 2020 / Accepted: 5 January 2021 / Published online: 30 January 2021

(c) The Author(s) 2021

\begin{abstract}
Azulene is an aromatic hydrocarbon that possesses a unique chemical structure and interesting biological properties. Azulene derivatives, including guaiazulene or chamazulene, occur in nature as components of many plants and mushrooms, such as Matricaria chamomilla, Artemisia absinthium, Achillea millefolium, and Lactarius indigo. Due to physicochemical properties, azulene and its derivatives have found many potential applications in technology, especially in optoelectronic devices. In medicine, the ingredients of these plants have been widely used for hundreds of years in antiallergic, antibacterial, and anti-inflammatory therapies. Herein, the applications of azulene, its derivatives and their conjugates with biologically active compounds are presented. The potential use of these compounds concerns various areas of medicine, including anti-inflammatory with peptic ulcers, antineoplastic with leukemia, antidiabetes, antiretroviral with HIV-1, antimicrobial, including antimicrobial photodynamic therapy, and antifungal.
\end{abstract}

\section{Graphical Abstract}

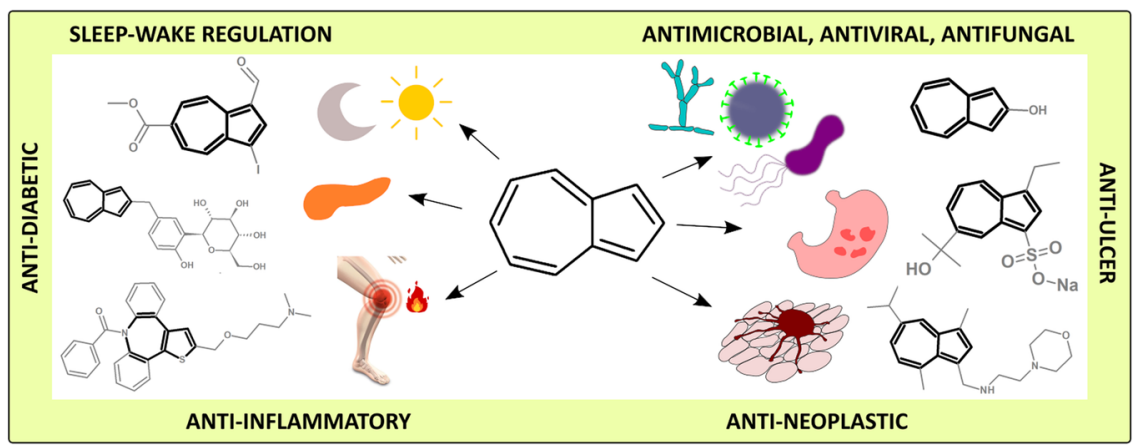

Keywords Azulene $\cdot$ Chamazulene $\cdot$ Conjugates $\cdot$ Medicinal chemistry $\cdot$ Molecular consortia

These authors contributed equally: Paweł Bakun, Beata CzarczynskaGoslinska

\section{Tomasz Goslinski}

tomasz.goslinski@ump.edu.pl

$\triangle$ Sebastian Lijewski slijewski@ump.edu.pl

1 Chair and Department of Chemical Technology of Drugs, Poznan University of Medical Sciences, Grunwaldzka 6, 60-780 Poznan, Poland

2 Chair and Department of Pharmaceutical Technology, Poznan University of Medical Sciences, Grunwaldzka 6, 60-780 Poznan, Poland

\section{Abbreviations}

AML acute myeloid leukemia

API active pharmaceutical ingredient

CHO Chinese hamster ovary cells

Clog P calculated partition coefficient

CMC critical micelle concentration

$\gamma_{\mathrm{CMC}}$ surface tension at CMC

COX cyclooxygenase

GAS-Na guaiazulene sulfate sodium GIST gastrointestinal stomach tumors

hSGLT1 human sodium-glucose transport protein 1

hSGLT2 human sodium-glucose transport protein 2

$\mathrm{IC}_{50}$ the half maximal inhibitory concentration

IL interleukin 
$\log \mathrm{P} \quad$ octanol-water partitioning coefficient

MEP molecular electrostatic field

MR molecular molar refractivity

MTT 3-(4,5-dimethylthiazol-2-yl)-2,5-diphenyltetrazolium bromide

MW molecular weight

NSAIDs nonsteroidal anti-inflammatory drugs

PACT antimicrobial photodynamic therapy

PBMCs peripheral blood mononuclear cells

$\mathrm{PGH}_{2} \quad$ prostaglandin $\mathrm{H}_{2}$

PPIs proton pump inhibitors

PVN paraventricular nucleus

ROS reactive oxygen species

SAR structure-activity relationship

SREBPs sterol regulatory element-binding proteins

STZ rats streptozotocin-induced diabetic rats

TNF- $\alpha$ tumor necrosis factor $\alpha$

TPSA topological polar surface area

$\mathrm{TXA}_{2}$ thromboxane $\mathrm{A}_{2}$

\section{Introduction}

Terpenes constitute a large family of organic compounds produced mainly in biochemical processes, starting from isoprene moiety 1 (Fig. 1). Examples of great importance in the animal world are carotenoids and vitamin A, which play a crucial role in numerous highly advanced biochemical processes in the human body. Vitamin $\mathrm{A}$ is known for improving many functions, including vision, gene transcription, immunity, hematopoiesis, embryonic development, and reproduction [1-4]. Another terpenic compound is squalene, a precursor of steroids, such as cholesterol, bile acid, vitamin D, and steroid hormones. A critical biochemical pathway that allows organisms to produce cholesterol-engaging squalene is the mevalonate pathway [5].

A source of many biologically-active terpenes are plants. Lycopene is a red carotenoid obtained from tomatoes and has proven to decrease risk factors, like LDL-cholesterol and IL-6, in cardiovascular diseases [6]. Another example is botulin, which is a triterpene revealing anticancer properties
[7-10], and also demonstrating an ability to inhibit sterol regulatory element-binding proteins (SREBPs). In this second way, it influences the reduction of biosynthesis of cholesterol and fatty acids [11]. In nature, terpenes also serve as a form of protection for plants from microorganisms, parasites, and herbivores.

Many terpenes exhibit biological activity and are used in the pharmaceutical industry. Essential oils obtained from plants e.g., menthol, thymol, and camphor, are active ingredients in nasal decongestants, chest creams, and cough medicines. They also act as antipruritics and anty-itching agents, due to their analgesic properties. Essential oils can also play a role as penetration enhancers in transdermal drug delivery systems [12, 13]. Triterpenoid compounds like oleanolic acid, ursolic acid, and their derivatives show antiinflammatory, anticancer, antidiabetic, antioxidant, and antibacterial effects [14, 15]. Noteworthy is paclitaxel, which is an anticancer drug isolated from Taxus brevifolia, and is also a diterpenoid belonging to the group of terpenes. What is more, it is approved for breast cancer treatment, AIDS-related Kaposi sarcoma, non-small cell lung cancer, and ovarian cancer [16].

Azulene $\mathbf{2}$ and its derivatives guaiazulene $\mathbf{3}$ and chamazulene $\mathbf{4}$ are aromatic hydrocarbons with unique chemical structure, physicochemical and biological properties. The azulene molecule consists of two condensed rings, cyclopentadiene and cycloheptatriene, and possesses $10 \pi$ electrons, so it obeys Hückel's rule. Moreover, azulene with its deep blue color is isomeric with colorless naphthalene and intensively absorbs light in the range of 500-700 nm [17, 18].

Azulene derivatives, due to their extraordinary physicochemical properties, have been proposed for many potential technical applications, such as molecular switching [19], sensors [20, 21], components of various optoelectronic devices [22, 23], and solar cells [24, 25]. However, since azulene compounds originate from medicinal plants, they draw the attention of researchers seeking new active pharmaceutical ingredients (API). Herbs containing terpenes have been applied in medicine since ancient times. Azulene derivatives occur naturally in mushrooms e.g., Lactarius indigo. Chamazulene can be found in camomile,

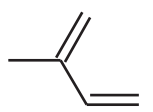

1

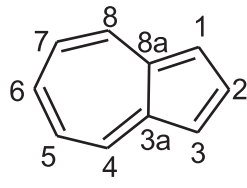

2
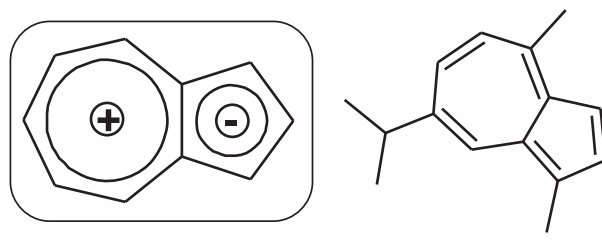

3

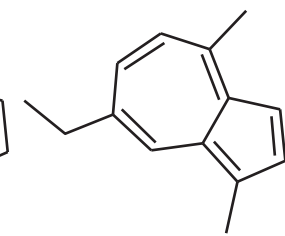

4

Fig. 1 Isoprene moiety $\mathbf{1}$, azulene $\mathbf{2}$, and its derivatives - guaiazulene $\mathbf{3}$, chamazulene $\mathbf{4}$. The inset presents unsymmetrical charge distribution in azulene 


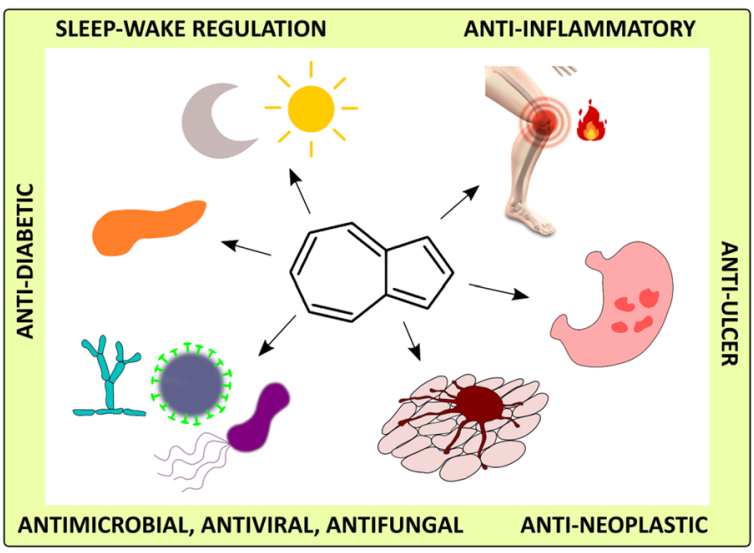

Fig. 2 Azulene, its derivatives, and potential applications in medicine

wormwood, or achillea oil and is known for antiallergic, antibacterial, and anti-inflammatory applications. These compounds have also revealed themselves to have some cosmetic uses, especially in soothing creams and ointments [17]. Chamomile oil oleogel formulation has been proven to be efficient against many different ailments, including pain, nausea, and vomiting. Photophobia and phonophobia occurring during migraine without aura were also effectively treated. Both of the aforementioned effects were confirmed in a randomized, double-blind, placebocontrolled clinical trial [26]. Guaiazulene, as an ingredient of local pomade, has provided rapid recovery in risky neonates with recalcitrant diaper dermatitis without any side effects [27].

Azulene is a very interesting scaffold for medicinal chemistry applications as it resembles bicyclic aromatics existing in many drugs. Moreover, it can be considered a structural isomer of naphthalene [28]. Modifications of azulene and its derivatives rely on substituents' addition or their conjugation with other biologically active molecules. Introducing substituents to the core of terpene can increase its solubility, modify absorption, and metabolism. However, the idea of its combining with other active compounds, pharmacophores, or moieties can lead to more profound results. The concept of creating molecular conjugates, hybrids, dimers, and other consortia brought drug discovery science to an entirely new unexplored dimension, which has been lately reviewed by Pawełczyk et al. [29]. Therefore, we present different azulene derivatives and conjugates, including selected molecular consortia, which exhibite attractive potential for medicine and pharmacy. Potential applications of these compounds' concern various areas of medicine, including anti-inflammatory with peptic ulcers, antineoplastic with leukemia, antidiabetes, antiretroviral with HIV-1, antimicrobial with antimicrobial photodynamic therapy, and antifungal (Fig. 2).

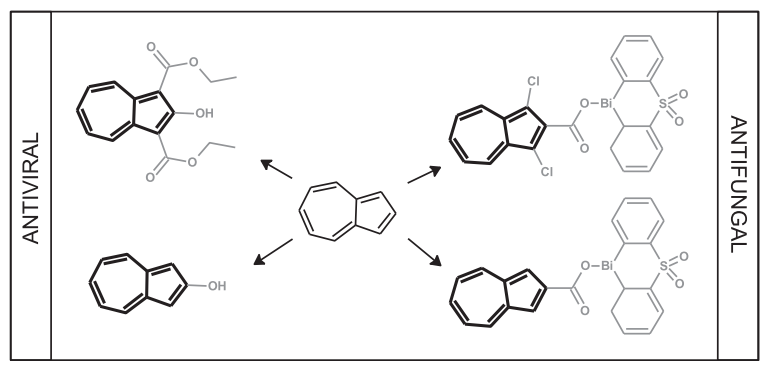

Fig. 3 Possible modifications of azulene derivatives of antiviral and antimicrobial potential

\section{Antiviral and antimicrobial activity}

One of the greatest achievements of mankind in the field of medicine was the invention of antibiotics about 100 years ago. Recent years have not revealed many new discoveries in the field of new antibacterial drugs, and more bacterial strains resistant to available antibiotics have appeared. Therefore, there is an increasing risk that the advent of the post-antibiotic era will see decreasing access to new drugs and therapies against pathogenic microorganisms [30]. Another significant problem the world has to tackle is how to deal with outbreaks of dangerous viruses in our environment, which affect human life such as AIDS or epidemics like Spanish flu in 1918, SARS in 2002-2004, MERS in 2012, and COVID19 in 2019-2021 [31]. Because of the above-mentioned problems, the development of new antibacterial and antiviral compounds is crucial. It seems that the azulene derivatives presented below could provide new insights and solutions to these issues. Various modifications of the azulene system of potential antiviral and antimicrobial activity are discussed below (Fig. 3).

As an introduction to the application of azulene and its derivatives in antimicrobial photodynamic therapy (PACT), some observations on the toxicity of these molecules, mainly related to the revealed phototoxic properties, should be considered. Such a study was performed by Chiang et al., who examined these natural products in terms of generation of singlet oxygen and other reactive oxygen species (ROS) after excitation with UVA light [32].

Damrongrungruang et al. investigated azulene's effect on peripheral blood mononuclear cells (PBMCs) viability and singlet oxygen formation in vitro [33]. They found out that azulene at concentrations $5-500 \mu \mathrm{M}$ when activated with light-emitting diode at $625 \mathrm{~nm}$ and light dose $4.2 \mathrm{~J} / \mathrm{cm}^{2}$ induced singlet oxygen generation. Another conclusion was that PBMCs viability was significantly reduced by azulene at a concentration of $15 \mu \mathrm{M}$ and red light densities of 4.2 , 100 , or $200 \mathrm{~J} / \mathrm{cm}^{2}$. The suggested mechanism of photodynamic reaction with azulene as photosensitizer was proceeding via the generation of ROS, which further caused damage to intercellular structures, including DNA. The 


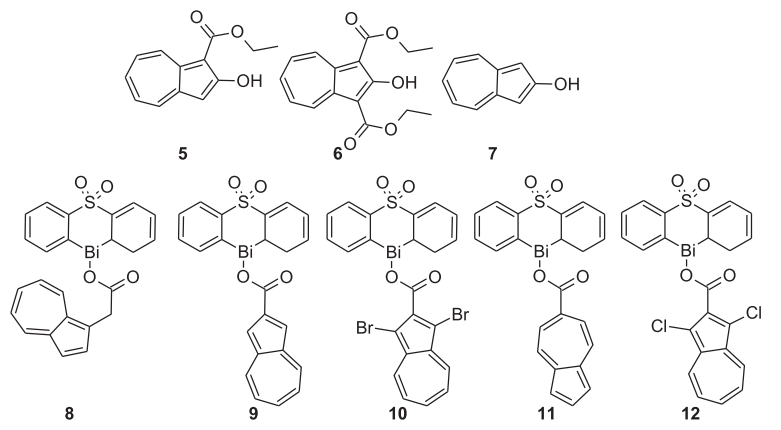

Fig. 4 Chemical structures of 2-hydroxyazulene derivatives 5-7 and heterocyclic organobismuth(III) carboxylates with azulene moieties 8-12

authors noted that a few improvements are necessary for further development of PDT in medicine, especially the length of irradiation time. The effects of azulene-lightoxygen action were analyzed in PACT study by Hayek et al. [34]. They performed microbial reduction in ligatureinduced periimplantitis in dogs using azulene as a photosensitizer in photodynamic therapy approach and found it equally efficient as conventional infection treatment. Also, PACT was found to be less invasive in comparison to other approaches. This study showed that Prevotella sp., Fusobacterium sp., and Streptococcus beta-haemolyticus were significantly reduced in both groups. During the treatment, $400 \mu \mathrm{L}$ of azulene $25 \%$ solution w/v was applied in the form of a paste based on $10 \%$ urea peroxide, $15 \%$ tween 80 in $75 \%$ carbowax as a vehicle. The $0.01 \%(\mathrm{w} / \mathrm{w})$ concentration of azulene in the paste was situated on scanned surfaces and exposed to diode GaAlAs laser operating at the wavelength of $660 \mathrm{~nm}$ and light dose $40 \mathrm{~mW}$ for $180 \mathrm{~s}$. The authors did not note any therapeutic effect without light activation, which indicates that azulene antimicrobial properties rely on photodynamic mechanisms. After treatment, no significant differences were observed between the groups, which suggests that photodynamic therapy is a noninvasive method that could be used to reduce microorganisms in periimplantitis. Recently, Nagai et al. demonstrated that azulenocyanine revealed the photodynamic antimicrobial effect on human infected dentine plates [35]. In the study, dentin plates extracted from human molars were infected through immersion in a solution of Streptococcus mutans. In the treatment procedure with $0.01 \%$ azulenocyanine $(0.1 \mathrm{ml})$ after 5 min period in darkness, the $1.5 \mathrm{~W}$ laser irradiation at $940 \mathrm{~nm}$ revealed the best results in terms of bactericidal effects by reduction of the colony count assay (CFU/ml) and by the ATP assay [35].

Despite photodynamic studies presented above, azulene and its derivatives demonstrated their own potential against viruses and microbes. In the study performed by Peet et al., 18 azulene derivatives were subjected to in vitro cytotoxicity and anti-HIV-1 assessment [36]. The authors researched the cytotoxicity of the compounds on the U2OS cell line. The least toxic compounds were examined in the first screening phase of the antiviral activity test using HIV-1-based viruslike particles for safe, sensitive, and fast evaluation of the antiretroviral activity. The highest potential was found for 2hydroxyazulenes 5-7 (Fig. 4), which were selected for the second phase of antiviral test to develop the inhibition of infectious HIV-1 virus replication TZM-bl cells. Finally, compound 5 was not active against the HIV-1 virus, but azulene derivatives $\mathbf{6}$ and $\mathbf{7}$ were recognized as active with the best score for 7 with $\mathrm{IC}_{50}$ at $8.5 \mu \mathrm{M}$ and selectivity index 7. The antiretroviral activities of azulene derivatives 5-7 were explained by the inhibition of reverse transcriptase. However, the authors did not exclude other antiviral mechanisms. Following the obtained results, the azulene derivatives can be considered as potential candidates for the development of antiretroviral agents.

The antimicrobial study was based on selected fungi and bacteria. Especially interesting was the study on the antifungal potential of azulene-organobismuth(III) carboxylates. Murafuji et al. synthesized a series of heterocyclic organobismuth(III) carboxylates, including azulene derivatives, and conducted qualitative antifungal assay on the yeast Saccharomyces cerevisiae W303-1A with DMSO in a parallel experiment as a negative control [37]. The highly lipophilic compounds, represented by 8-12, exhibited a satisfactory level of inhibition of fungal growth (Fig. 4). The cationic heterocyclic bismuthcontaining scaffold was responsible for inhibitory activity, whereas the carboxylate anion positively affected the drug absorption and bioavailability.

\section{Anti-inflammatory activity}

Inflammation is a physiological reaction of an organism exposed to stress factors such as tissue damage, injuries, cancers, and arthritis. In case of minor contusions and sports injuries, especially in young people, inflammation is even welcome because it helps tissues heal [38]. However, when inflammation becomes chronic, some therapeutic actions are needed. The two most important groups of anti-inflammatory drugs are nonsteroidal anti-inflammatory drugs (NSAIDs), working through cyclooxygenase (COX) inhibiting mechanism, and glucocorticoids, which suppress the immune response and inhibit the synthesis of two main products of inflammation: prostaglandins and leukotrienes. Unfortunately, both groups cause many side effects, and because of that, new approaches in the therapy of chronic inflammation are considered necessary. Various modifications of azulene derivatives of potential anti-inflammatory activity have already been obtained and are discussed below (Fig. 5).

Plants traditionally used in medicine, e.g., camomile (Matricaria chamomilla) and yarrow (Achillea millefolium), 
exhibit an anti-inflammatory effect due to the presence of azulene derivatives. Camomile extract was proved to interfere selectively with the COX-2 pathway similarly to the drug sulindac [39]. Moreover, a study performed by $\mathrm{Ma}$ and coworkers showed that chamazulene significantly protects against complete Freund's adjuvant-induced osteoarthritic inflammation in a rat model [40]. Therefore, chamazulene can be recommended as a therapeutic agent for clinical trials against osteoarthritic inflammation. Also, the combinations of azulene derivatives with various molecules reveal attractive anti-inflammatory potential. For example, Nihei et al. studied the efficacy of a combination of sodium azulene sulfonate and L-glutamine to treat oral mucositis caused by anticancer drugs [41]. Patients using sodium azulene sulfonate L-glutamine suspension as a mouthwash three times a day, reported fewer or less severe cases of mucositis in comparison to a control group.

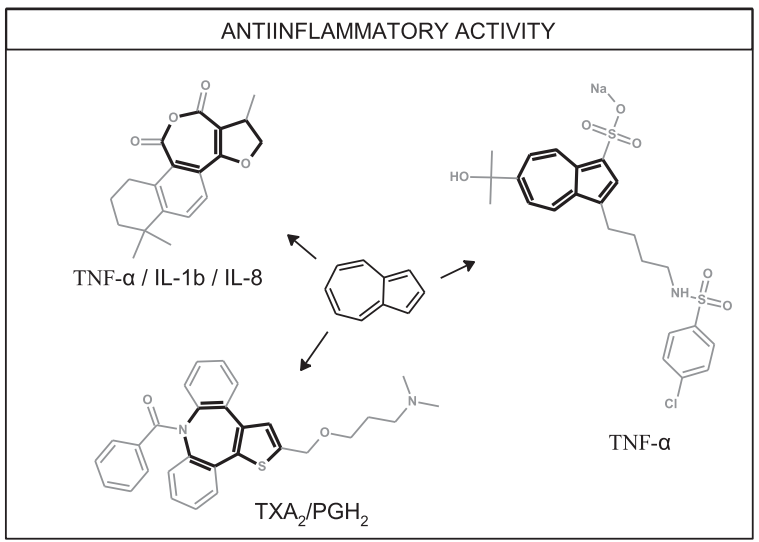

Fig. 5 Possible modifications of azulene derivatives of antiinflammatory potential; TNF- $\alpha$ - tumor necrosis factor $\alpha$, IL-1b/ IL-8 - interleukins $1 \mathrm{~b}$ and $8, \mathrm{TXA}_{2} / \mathrm{PGH}_{2}$-thromboxane $\mathrm{A}_{2}$ /prostaglandin $\mathrm{H}_{2}$
Considering its high level of safety and lack of alternatives available to fight oral mucositis induced by anticancer treatment, this procedure seems to offer the chance for the patients to have a better quality of life while fighting cancer.

Azulene scaffold can be encountered among compounds isolated from Salvia miltiorrhiza var. alba roots, which are used in traditional Chinese medicine. Ma et al. evaluated the anti-inflammatory activities of tanshinones isolated from Salvia miltiorrhiza var. alba roots in THP-1 macrophages [42]. These compounds have been applied in the treatment of cardiovascular diseases in local clinical practice. Hexahydrotrimethylnaphthoazulenedione 13 showed antiinflammatory potency to inhibit the production of TNF- $\alpha$, IL-1 $\beta$, and IL-8 in lipopolysaccharide-activated THP-1 macrophages (Fig. 6).

Related potential applications of azulene derivatives were presented by Yokota et al., who focused on finding thromboxane $\mathrm{A}_{2}$ /prostaglandin $\mathrm{H}_{2}$ antagonists with potential use in the treatment of myocardial ischemia, asthma, or peptic ulcer [43]. They obtained a series of new azulene-based compounds and conducted two in vitro experiments on isolated rat aorta and platelet-rich rabbit plasma. These tests enabled SAR analysis and selection of 6-mono- and 6-dihydroxylatedisopropylazulene derivatives of 4-chlorobenzenesulfonamide 3 -substituted azulene derivatives for the in vivo experiments in mice. The results of the in vivo experiment showed that pre-treatment with 14 and 15 in a $3.0 \mathrm{mg} \mathrm{kg}^{-1}$ p.o. dose prevented U-46619-induced sudden death in mice.

Ozimec Landek et al. synthesized two series of azulene compounds fused with two benzene rings [44, 45] and analyzed the influence of new compounds on tumor necrosis factor $\alpha$ (TNF- $\alpha)$ production. TNF- $\alpha$ can be considered an important inflammatory factor. In these series of derivatives, two carbon atoms of azulene scaffold were replaced with heteroatoms, mainly sulfur. Both series of 1-

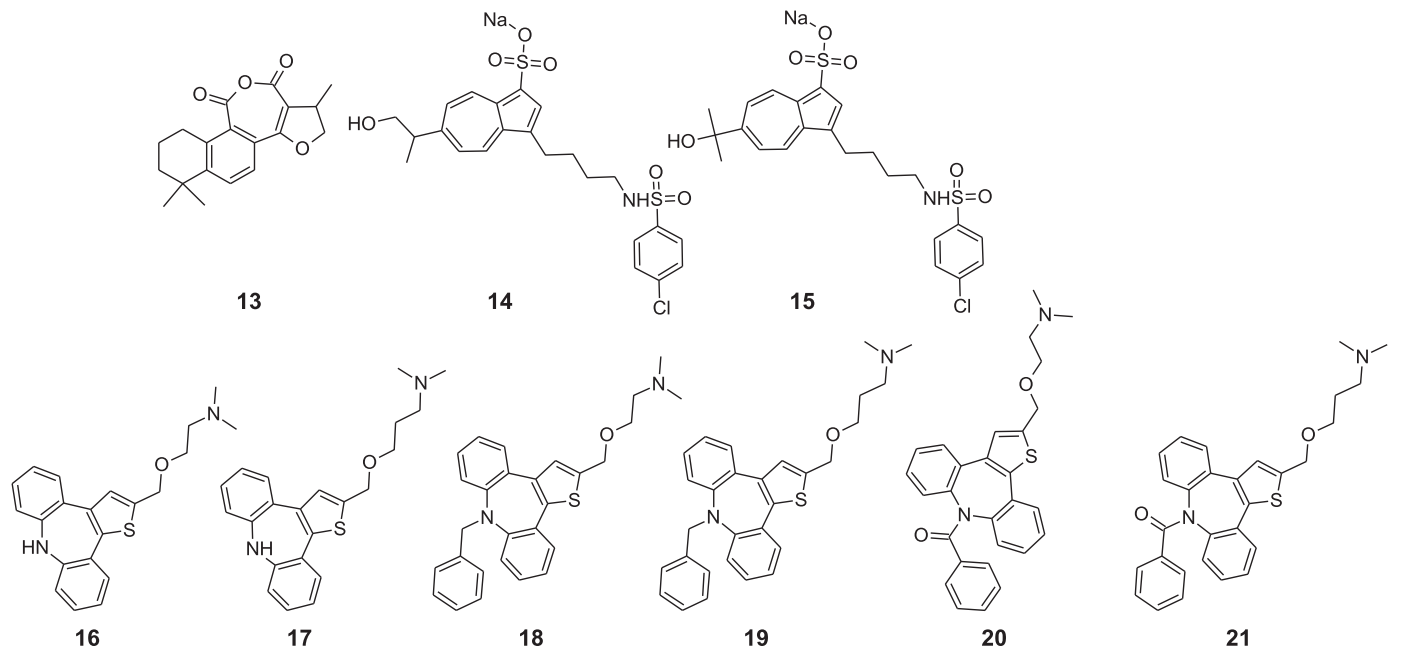

Fig. 6 Chemical structures of 13-21 


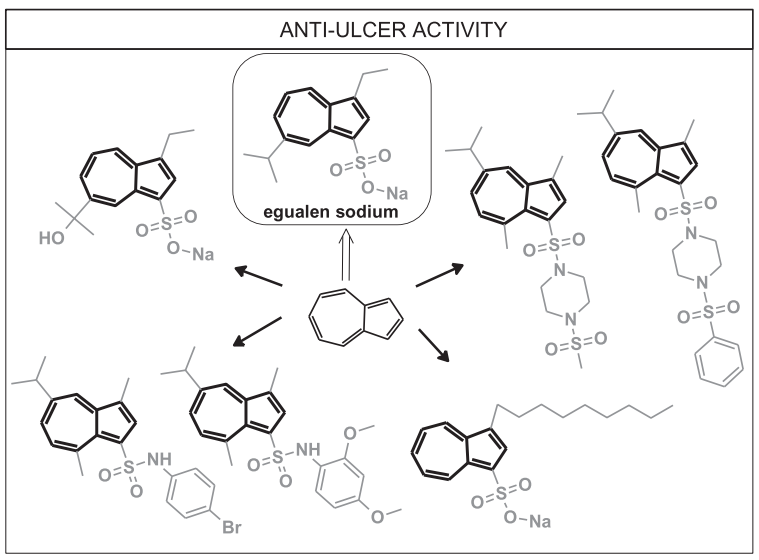

Fig. 7 Possible modifications of azulene derivatives of antiulcer potential

thia- and 2-thiaazulene derivatives showed in vitro potency to inhibit TNF- $\alpha$ production in lipopolysaccharide activated human peripheral blood mononuclear cells assay. Compounds 16-21 belonging to series with aminoalkoxy chain at $\mathrm{C}-2$ position showed potency to inhibit TNF- $\alpha$ production in vitro in low micromolar range with $\mathrm{IC}_{50}$ values for the most potent compounds in the range of $1-3 \mu \mathrm{M}$. However, none of these compounds exhibited the ability to inhibit other important inflammation factors like p38 kinase or COX-2 enzyme.

\section{Antiulcer activity}

Peptic ulcer disease is a prevalent disorder reported by patients and physicians. It is estimated that about $4 \%$ of the population suffers from peptic ulcers, and about $10 \%$ will develop it during their lifetime [46]. One of the most important groups of drugs used in the treatment of peptic ulcers is called proton-pump-inhibitors (PPIs) and comprises molecules like omeprazole, pantoprazole, and lansoprazole. PPI is the most effective group of drugs used to diminish hydrochloric acid release in the stomach. Even PPIs, which are considered safe, cause side effects. Therefore, new classes of antiulcer drugs are desirable. The success of Egualen, which is a sodium salt of 3-ethyl-7propan-2-yl-azulene-1-sulfonic acid applied in the treatment of gastric ulcers in Japan under the tradename Azuloxa [47], shows that there is enormous potential for azulene scaffold. Various modifications of the azulene system of potential antiulcer activity have already been performed and are discussed below (Fig. 7).

Yanagisawa et al. studied the anti-peptic activity of compounds related to the metabolites of known APIsodium 3-ethyl-7-isopropyl-1-azulenesulfonate (22, KT1-32, egualen sodium) (Fig. 8) [48]. They synthesized six compounds (23-28), of which five molecules 24-28 containing 3-alkyl-1-azulenesulfonate moiety are the metabolites of $\mathbf{2 2}$ and assessed their antiulcer activity. Compounds $\mathbf{2 2}$ and $\mathbf{2 3}$ were treated as reference compounds in the study. Metabolites 24-28 showed lower anti-peptic activity than 22, whereas the lowest activity was revealed by compounds 27 and 28.

Fujio et al. obtained a very similar compound $\mathbf{3 0}$ to the series obtained in the above-discussed study [49]. The difference was the length of the carbon chain in the 3rd position. Afterward, they assessed the surface and antipeptic activity of 30 in comparison to reference molecule 29. Results of surface properties included the following parameters: critical micelle concentration $(\mathrm{CMC})$, surface tension at CMC $\left(\gamma_{\mathrm{CMC}}\right)$, efficiency in surface tension reduction $\left(\mathrm{pC}_{20}\right.$, the negative logarithm of the surfactant concentration required to reduce the surface tension of solvent by $20 \mathrm{nN} ; \mathrm{m}^{-1}$ ). It was found that $\mathbf{3 0}$ exhibits higher antipeptic activity than a reference compound 29, considering the $\mathrm{CMC}$ and $\mathrm{IC}_{50}$ (concentration which inhibits peptic activity by $50 \%$ ) parameters with values such as 0.31 and $0.91 \mathrm{mmol} \mathrm{kg}^{-1}$, respectively. The observed activity can be explained as the hydrophobic binding of the amphiphilic molecule $\mathbf{3 0}$ to the pepsin's hydrophobic active pocket. To sum up, the new compound $\mathbf{3 0}$ presented slightly less surface activity than its structural isomer 4-decyl-1naphthalenesulfonate 31, probably due to the dipole moment within the azulene moiety. Moreover, 30 exhibited higher antipeptic activity than $\mathbf{2 9}$, below half of the CMC, above which level the antipeptic activity of $\mathbf{3 0}$ was weakened, probably as a result of the unfolding of bovine serum albumin, which promotes its digestion by pepsin.

Zhang et al. synthesized another series of azulene derivatives, which present 5-isopropyl-3,8-dimethylazulene conjugated to arylamines 32-38 (Fig. 9) [50]. The antigastric ulcer activity was studied in vivo on 200 Kunning mice with ethanol-induced gastric ulcers. The structure-activity relationship (SAR) of new compounds was investigated in mice which were treated with an oral dose of suspension containing in its composition carboxymethyl cellulose sodium as an additive and tested compounds-test group, omeprazole-drug reference group, precursor guaiazulene sulfate sodium (GAS-Na), and 5\% of carboxymethyl cellulose sodium alone-control group. The oral route's applied dose of suspension was administered in an amount of $0.4 \mathrm{~mL} / 20 \mathrm{~g}$ once a day for five consecutive days. Thirty minutes after applying the last dose, mice were given $0.5 \mathrm{~mL}$ of anhydrous ethanol orally, and then after a further $30 \mathrm{~min}$, the animals were euthanized. Subsequent gastrectomy allowed for the assessment of ulcerative lesions. The research demonstrated that compounds 32-38 can be considered as promising antigastric ulcer agents. Moreover, a comparison of arylamino-substituted compounds with alkylamino substituted compounds showed advantages of the first group over the second for antiulcer 


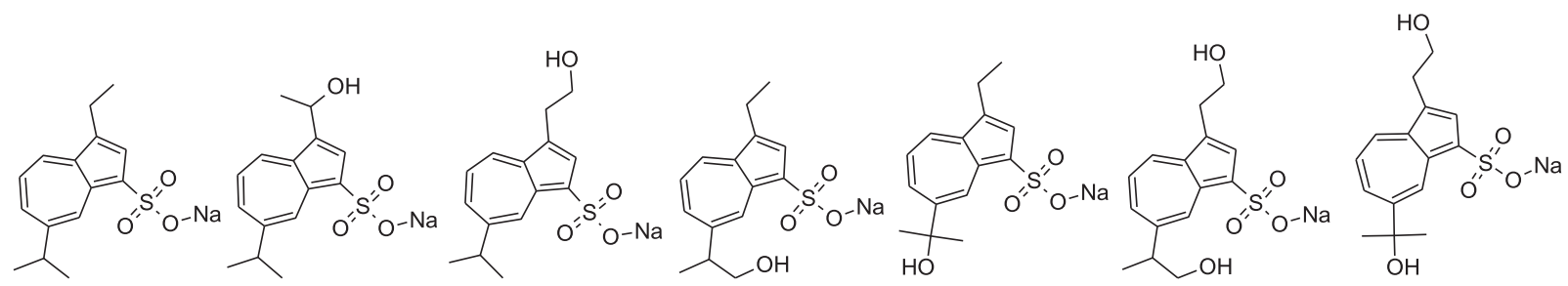

22

23

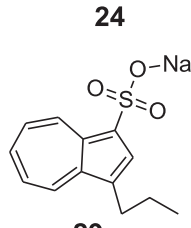

29

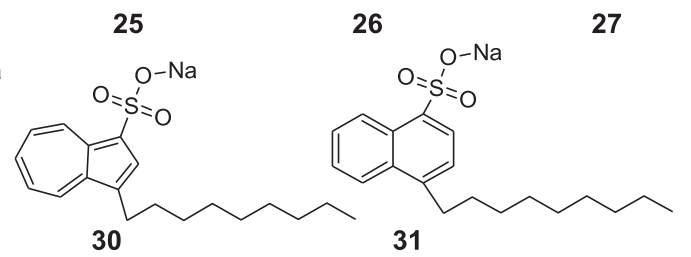

Fig. 8 Chemical structures of 22-31

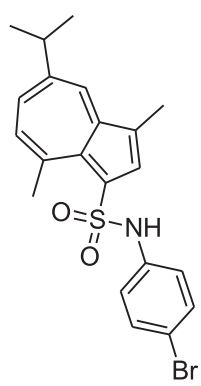

32

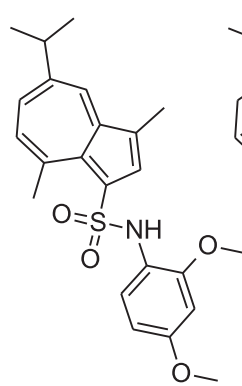

33

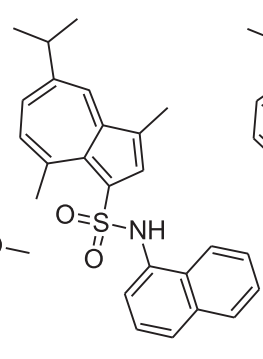

34

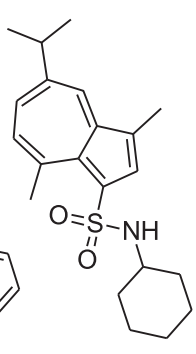

35

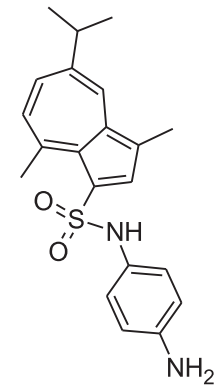

36

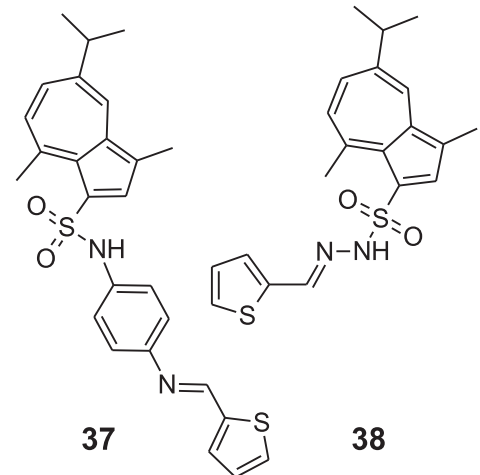

Fig. 9 Chemical structures of 32-38

effectiveness. The results of the study gave reason for optimism as some molecules presented the best antiulcer activity with ulcer index values lower than that observed for the reference drug omeprazole.

Cao et al. studied antigastric ulcer activity in vivo of guaiazulene derivatives on 221 mice divided into 28 groups [51]. They obtained guaiazulene sulfonate derivatives with a double sulphonylamino motif due to piperazine presence and studied their antigastric ulcer activity through an ethanolinduced gastric ulcer model method. All studied guaiazulene derivatives presented antigastric ulcer activity. It is worth noting that compounds 39-46, showed a significant reduction of gastric ulcers, whereas the most promising compounds $\mathbf{3 9}$, 42, 43 exhibited even better antiulcer activity than the firstline drug omeprazole (Fig. 10).

The researchers also provided SAR analysis. Many parameters such as topological polar surface area (TPSA), octanol-water partitioning coefficient $(\log P)$, molecular molar refractivity (MR), calculated partition coefficient (Clog P), molecular weight (MW) were taken into account and compared. Unfortunately, there were not enough data to prove the correlation between the mentioned parameters and biological activity. Nonetheless, the authors noted some dependencies. For example, compounds possessing two sulphonylamino moieties revealed better activity than other compounds. In general, derivatives with electronwithdrawing substituents exhibited better activity than molecules with electron-donating groups, whereas the bromine element played an important role in enhancing activity. The mechanism of action of guaiazulene derivatives is not known at the moment. Scientists proposed two probable explanations: surface coverage and multifunctional group synergistic mechanisms.

\section{Antineoplastic activity}

Cancers and other neoplasms are still a significant health threat with high expenditure for cancer care, which in the USA in 2018 reached ca. 150 billion dollars. Moreover, cancer is still one of the leading causes of death worldwide, despite extensive research on new antineoplastic medications. In 2018, there were more than 18 million new cases and more than 9 million cancer-related deaths worldwide. Approximately $39.5 \%$ of men and women will be diagnosed with cancer at some point in their lives [52]. Regardless of 


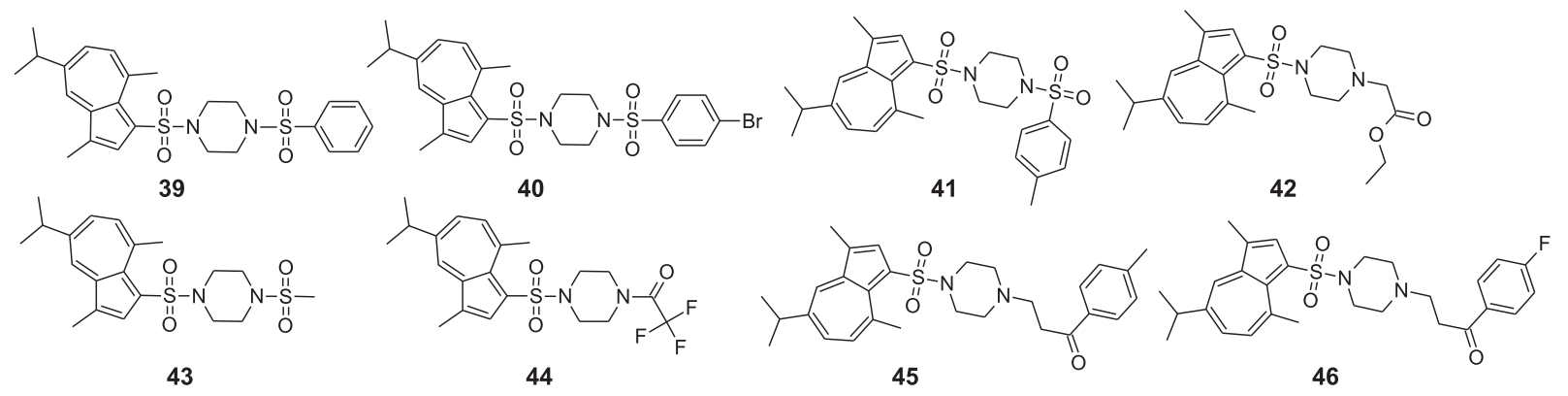

Fig. 10 Chemical structures of 39-46

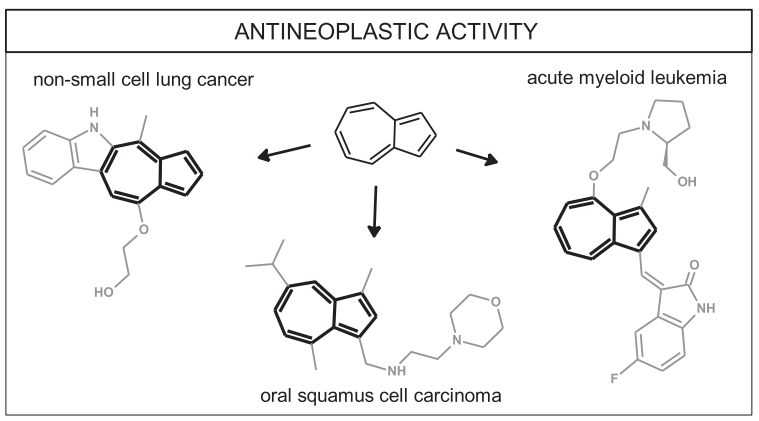

Fig. 11 Possible modifications of azulene derivatives of anticancer potential

the progress of science and medicine, there is a great need for new treatment options for these diseases. To fight this ubiquitous threat, scientists work on sophisticated strategies such as retrospection based on traditional medicine and herbal remedies, variations with light in photodynamic therapy, and nanomedicine.

Azulene moiety, as an element of molecular consortia, raises great hope for effective anticancer drugs. Photodynamic activation with red laser light and guaiazulene revealed the generation of singlet oxygen and suppression of inflammatory markers in peripheral blood mononuclear cells [53]. The chamazulene/camphor-rich essential oils containing $63 \%$ of chamazulene from Artemisia arborescens plants collected in Sicily showed promising activity on studied melanoma cancer cells with potential to trigger apoptotic death [54]. It is worth noting that, according to some studies, chamazulene is an even more potent antioxidant than ascorbic acid and $\alpha$-tocopherol [55]. Various modifications of azulene system of potential antineoplastic activity, which have already been performed, are discussed below (Fig. 11).

Uehara et al. obtained a series of 10 alkylaminoguaiazulene derivatives towards both cancer and normal cells [56]. Cytotoxicity was assessed using the 3-(4,5-dimethylthiazol2-yl)-2,5-diphenyltetrazolium bromide (MTT) method. Moreover, apoptosis-inducing activity was evaluated by cleavage of poly ADP-ribose polymerase and caspase- 3 with western blot analysis. It was found that with the increasing length of the alkyl group of alkylaminoguaiazulene derivatives, cytotoxicity increased, whereas the introduction of oxygen, nitrogen, or sulfur atom into the alkyl group slightly reduced cytotoxicity. Among compounds studied, guaiazulene substituted with morpholine $\mathbf{4 7}$ showed very high tumor specificity, as well as apoptosis-inducing activity against oral squamous cell carcinoma (Fig. 12). In another study, alkoxyl guaiazulene-3-carboxylates were also considered as potential candidates for anticancer medicines or leading structures for further derivatization [57].

Hong et al. synthesized a group of 14 azulene-indoles using a microwave-assisted method [58]. After that, an evaluation of their in vitro activity against 60 human cancer cell lines, including melanoma, leukemia, lung, colon, renal, ovarian, central nervous system, breast, and prostate lines, was performed according to standard National Cancer Institute protocols. Results indicated that compound $\mathbf{4 9}$ could be considered a potent inhibitor of EKVX non-small cell lung cancer cell line growth with $\mathrm{IC}_{50} 1.00 \mu \mathrm{M}$ and HS578T breast cancer cell line with $\mathrm{IC}_{50} 0.93 \mu \mathrm{M}$. Also, other compounds $\mathbf{4 8}$ and $\mathbf{5 0}$ showed interesting antineoplastic activity. Molecule $\mathbf{4 8}$ was found a selective and potent growth inhibitor of K-562 leukemia cancer cell line with $\mathrm{IC}_{50} 0.51 \mu \mathrm{M}$, and revealed good inhibition properties in HOP-92 non-small cell lung cancer cell line with $\mathrm{IC}_{50}$ $1.38 \mu \mathrm{M}$. Azulene derivative $\mathbf{5 0}$ presented good potential against HOP 92 cell line with $\mathrm{IC}_{50} 0.56 \mu \mathrm{M}$ and PC-3 prostate cancer cell line with $\mathrm{IC}_{50} 1.41 \mu \mathrm{M}$. The mechanism of action of the compounds mentioned above was not indicated.

A very interesting study on a series of azulene derivatives as potent multi-receptor tyrosine kinase inhibitors for the treatment of acute myeloid leukemia (AML) or gastrointestinal stomach tumors (GIST) was performed by Chen et al. [59]. After synthesis and screening tests, compound $\mathbf{5 1}$ presented high cytotoxicity against human peripheral blood cell line MV4-11 with $\mathrm{IC}_{50}$ values in the submicromolar range. Simultaneously, it also inhibited KDR, cKIT, PDGFR $\beta$, and FLT-3 receptors. Afterward, scientists analyzed the pharmacokinetics of $\mathbf{5 1}$ in rats and measured the 


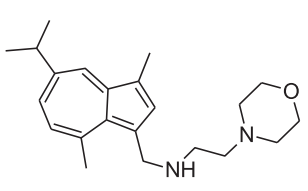

47

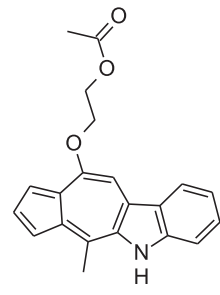

48

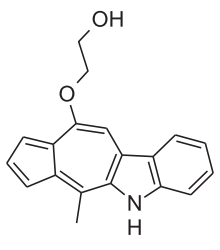

49

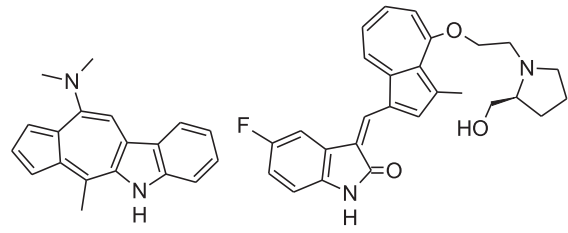

50

$51(E / Z$ 1.6:1)

Fig. 12 Chemical structures of $\mathbf{4 7 - 5 1}$

essential parameters after administering its single intravenous or oral dose. The next experiment was conducted on human leukemia MV4-11 xenografts in BALB/c nude mice and revealed that on the 30th day after the beginning of treatment, using $50 \mathrm{mg} / \mathrm{kg}$ dose twice a day, tumor growth inhibition by $\mathbf{5 1}$ was $99 \pm 0.82 \%$. The results indicate that compound $\mathbf{5 1}$ has a great potential to become a perspective antileukemia agent, and it can undoubtedly move to the next phase of research-clinical trial. Therefore it can be considered as a potent FMS-like tyrosine kinase 3 inhibitor and antileukemia agent.

\section{Antidiabetic activity}

Diabetes is a prevalent metabolic disorder characterized by insulin resistance and persistent hyperglycemia. Each year nearly 85 thousand USA residents die due to diabetes, according to the Centers of Disease Control and Prevention U.S. Department of Health \& Human Services [60], thus making diabetes the 7th most common cause of death in the USA. Many research groups worldwide do their best to propose new, more efficient, and patient-friendly therapies for this disease. Various modifications of the azulene system of potential antineoplastic activity, which have already been performed, are discussed below (Fig. 13).

For this purpose, Ikegai et al. synthesized a series of Cglucosides with azulene in the aglycon moiety, starting from a previously examined compound $\mathbf{5 2}$ [61]. Expected inhibitory activity toward human sodium-glucose transport protein 1 (hSGLT1) and human sodium-glucose transport protein 2 (hSGLT2) was evaluated in vitro using Chinese hamster ovary cells (CHO) expressing hSGLT1 or hSGLT2. The researchers measured $\mathrm{IC}_{50}$ values regarding to hSGLT2 and selectivity versus hSGLT1 of the essential compounds: $\mathbf{5 2}(99 \mathrm{nM}, 140$ fold), $\mathbf{5 3}$ ( $22 \mathrm{nM}, 590$ fold), $\mathbf{5 4}(8.9 \mathrm{~nm}, 280$ fold) in at least two independent experiments (Fig. 14). Moreover, preclinical tests on $\mathrm{KK} / \mathrm{A}^{\mathrm{y}}$ type 2 diabetic mice were conducted to confirm the antihyperglycemic effect of 53 in vivo. This test showed that a single oral administration of 53 with a dose $3 \mathrm{mg} / \mathrm{kg}$ reduced blood glucose levels

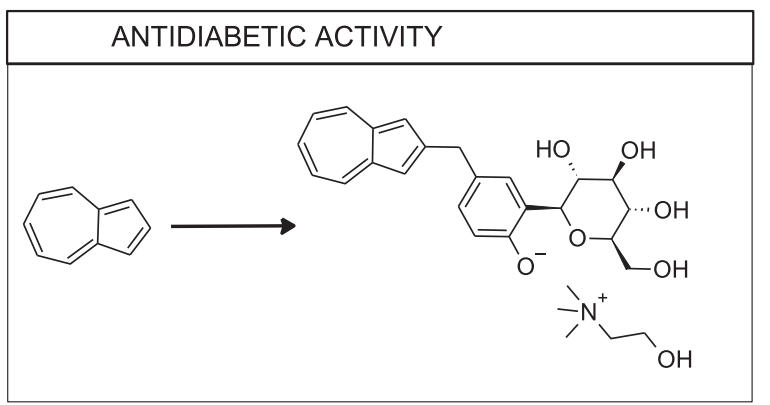

Fig. 13 Possible modifications of azulene derivatives of antidiabetic potential

significantly by $46 \%$ compared to the vehicle. Afterward, the optimization of molecule $\mathbf{5 3}$ was performed, leading to the synthesis of $\mathbf{5 4}$, which was finally chosen as the most promising compound from the whole series and proposed to reach clinical trial in the form of mono choline salt 55, named YM543. Pharmacokinetics studies on normal rats were carried out to assess this compound in the living organism. Results obtained after administering a single $1.0 \mathrm{mg} / \mathrm{kg}$ dose intravenously or a single $3 \mathrm{mg} / \mathrm{kg}$ dose orally revealed fast oral absorption with $T_{\max } 0.5 \mathrm{~h}$, bioavailability $29 \%$, clearance $2483 \mathrm{~L} / \mathrm{h} / \mathrm{kg}$, the volume of distribution $3360 \mathrm{~L} / \mathrm{kg}$. Renal drug concentration was 23 times higher than that in plasma. Oral administration of $0.3-3.0 \mathrm{mg} / \mathrm{kg}$ dose of $\mathbf{5 4}$ resulted in a dose-dependent increase in urinary glucose excretion that lasted over $12 \mathrm{~h}$ for the dose of $0.3 \mathrm{mg} / \mathrm{kg}$ or higher. Moreover, the compound exhibited potent and long-lasting antihyperglycemic activity in both streptozotocin-induced diabetic rats (STZ rats, type 1 diabetes model) and $\mathrm{KK} / \mathrm{A}^{\mathrm{y}}$ mice without decreases into the hypoglycaemic range.

\section{Various cardiac, vascular, and neurological disorders}

An interesting study was provided by Löber et al., who developed the synthesis path of azulene derivatives and assessed their affinities for the monoaminergic $G$ protein- 


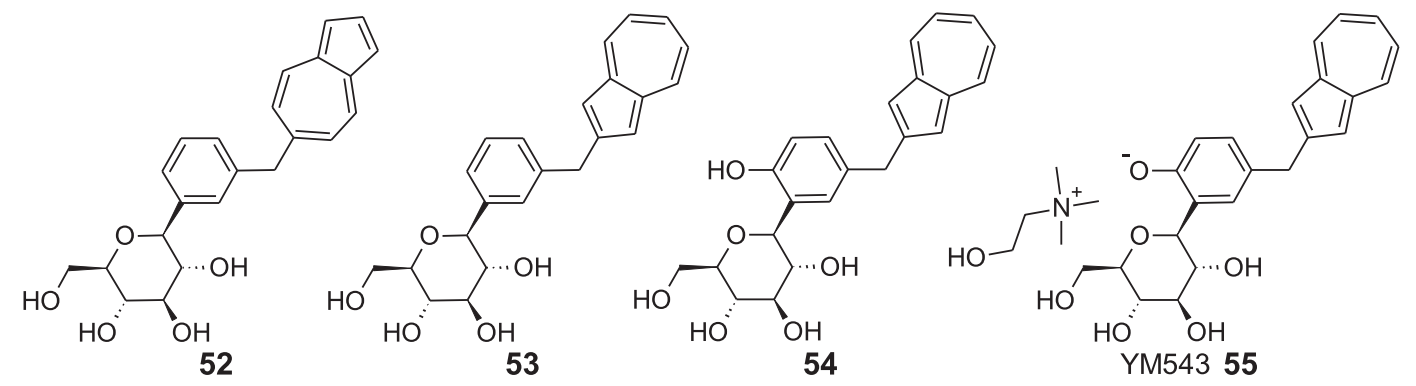

Fig. 14 Chemical structures of 52-55

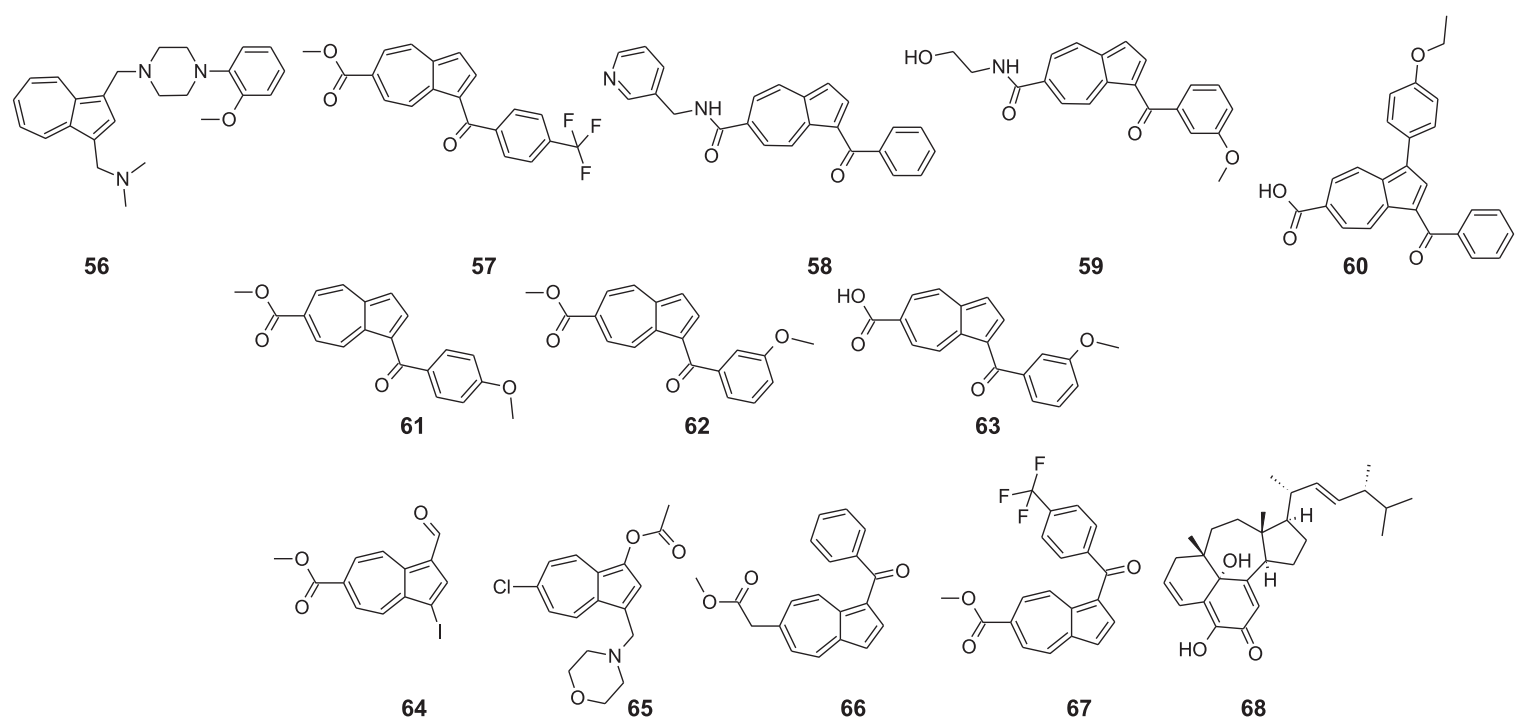

Fig. 15 Chemical structures of 56-68

coupled receptors, including dopamine, serotonin, histamine, $\alpha$-adrenergic receptor subtypes, and performed SAR analysis [62]. The authors synthesized a series of azulenylmethylpiperazines inspired by previously examined compound FAUC 3019, a partial agonist of dopamine $\mathrm{D}_{4}$ receptor with a potential application in therapy of erectile dysfunction. Receptor binding properties were tested in vitro on Chinese hamster ovary cells. In vivo test of the most promising molecule $\mathbf{5 6}$ (Fig. 15) was conducted on 32 male rats. Compound $\mathbf{5 6}$ proved to induce penile erection in male rats after systemic (subcutaneous, sc) administration and injection into the paraventricular nucleus (PVN). In low concentrations, the effectiveness of $\mathbf{5 6}$ was better than that of the reference-apomorphine. Azulene derivative 56 revealed excellent $\mathrm{D}_{4}$ receptor affinity, good selectivity, and was considered as $\mathrm{D}_{4}$ partial agonist with $\mathrm{EC}_{50}$ at $0.41 \mathrm{nM}$. The rationale for incorporation of azulene moiety into novel compounds can be explained by the specific charge distribution within this molecule with a significant negative molecular electrostatic field (MEP) below and above the five-membered ring, and a positive MEP at the sevenmembered ring (Fig. 1). Moreover, the large dipole moment of azulenes made molecule $\mathbf{5 6}$ easily recognizable for the dopaminergic $\mathrm{D}_{4}$ receptor. The results proved that the new compound 56 could be considered for further study towards erectile dysfunction. Nevertheless, more study in this field is needed, including comparative research on the effectiveness and safety profile of newly synthesized compound $\mathbf{5 6}$ and already approved for the treatment of erectile dysfunction with first-line drugs like sildenafil and tadalafil.

Turku et al. used in silico analytic software to propose compounds for synthesis of orexin (hypocretin) OX1 and OX2 receptor ligands [63]. As the receptor is involved in the sleep-wake regulation, the antagonists are considered to treat insomnia. Moreover, the agonists are suspected of becoming useful in treating daytime sleepiness, narcolepsy, and certain cancer types. Besides, some ligands can act as potentiators with expected application in orexin receptor activation therapies when the production of endogenous peptides is not fully terminated. In the research, seven potentiators and two weak dual orexin receptor agonists were found. The activity assessment consisted of monitoring $\mathrm{Ca}^{2+}$ response in Chinese hamster ovary (CHO)$\mathrm{K} 1$ cells heterologously expressing high densities of human 
$\mathrm{OX}_{1}$ and $\mathrm{OX}_{2}$ receptors. Calcium ions elevation is considered to be a prominent response to orexin receptor activation. The study confirmed that compounds $\mathbf{5 7 - 6 0}$ acted as weak orexin receptor agonists, whereas compounds 61-63 potentiated the response to orexin- $\mathrm{A}$ on $\mathrm{OX}_{1}$ receptors by 1,4-, 1,6- and 1,3-fold, respectively, at $10 \mu \mathrm{M}$. The most critical finding of SAR analysis was the observation that agonism and potentiation are related to the presence of bicyclic aromatic ring moiety substituted with two hydrogen bond acceptors (1-position, benzoyl; 6-position, carboxyl/ ester) within 7-8 $\AA$ of each other. Moreover, it was found that subtle changes in the structure cause changes in the activity, possibly because the overlapping of binding sites occurs. It seems an interesting research direction, but to even think about the future medical application of mentioned compounds, more experiments are necessary, especially toxicology assessment and pharmacokinetics in vivo.

The orexin system is critical in terms of sleep-wake regulation, stress response, and insomnia. Therefore there is interest in small molecular potentiators that enhance the effects of endogenous neuropeptides, especially orexin-A and orexin-B. In another study, Leino et al. screened a library of 70,000 synthetically accessible azulene-based compounds targeting orexin-based receptors [28]. The most promising molecules 64 and 65 showed $K_{\mathrm{i}}$ values in the low micromolar range 3-9 $\mu \mathrm{M}$, whereas compounds 66 and 67 acted as weak OX receptor agonists. Three other compounds exhibited a concentration-dependent potentiation of response to orexin-A at the $\mathrm{OX}_{1}$ but not $\mathrm{OX}_{2}$ receptors with twofold potentiation at $10 \mu \mathrm{M}$.

Although new azulene derivatives come from synthetic reactions in the laboratory, the plethora of their derivatives are still present in various plants. An excellent illustration of this is ergosterol ganotheaecolin A (68), found in mushroom Ganoderma theaecolum by Luo et al. [64]. The fungus is commonly used in traditional Chinese medicine for the treatment of neurological disorders. After isolation and confirmation of structure, scientists conducted for this molecule in vitro evaluation of neurite outgrowthpromoting activity in PC12 cells, using NGF as control. The results indicated that $\mathbf{6 8}$ could stimulate cell differentiation in a dose-dependent manner and reached the maximum effect at $10 \mu \mathrm{M}$. Much research still needs to be performed in this area, but $\mathbf{6 8}$ revealed the potential to become a cure for neurological diseases in the future.

\section{Conclusion}

Terpenes constitute a large family of organic compounds produced mainly in biochemical processes, starting from isoprene moiety. The most important example of this group is vitamin A which is involved in many biochemical processes such as vision, gene transcription, immune function, hematopoiesis, embryonic development, and reproduction. Another important terpenic compound is squalene, a precursor of cholesterol, bile acid, vitamin $\mathrm{D}$, and steroid hormones. In nature, terpenes often serve as plant protection from microorganisms, parasites, or herbivores, and because of that, many biologically-active terpenes are obtained from plants. To the terpene family created by nature belong, among others: lycopene, botulin, menthol, thymol, camphor, paclitaxel, oleanolic acid, ursolic acid, chamazulene, and guaiazulene. Most terpenes reveal a long list of traditional uses in herbal extracts due to their anti-inflammatory, anticancer, antidiabetic, antioxidant, or antibacterial activity.

Azulene, chamazulene, and guaiazulene have been known for ages and widely applied in medicine. In this review, we presented new potential applications of their derivatives in medicine and pharmacy. Azulene scaffold exhibits an interesting perspective for medicinal chemistry as it can be considered a structural isomer of naphthalene. Therefore, introducing the bicyclic azulene hydrocarbon into various molecular consortia leads to compounds with a vast spectrum of biological activities. The azulene derivatives may be potentially applied in the therapy of peptic ulcers, leukemia, lung cancer, diabetes, and various viral, fungal, and microbial infections. In this review, we presented many biological studies, which were performed in vitro on various cell lines, e.g., PBMCs, U2OS, TZM-bl, EKVX, HS578T, K-562, HOP-92, PC-3, MV4-11, CHO, (CHO)-K1, PC12, and in vivo on rats and mice. The most promising applications of azulene derivatives were proposed for the treatment of peptic ulcer disease. It is worth noting that in the biological study, some of the azulene derivatives revealed even better antiulcer activity than a reference drug omeprazole. Another promising biological activity of azulene derivatives was their influence on the growth of selected cancer cell lines e.g., K-562 leukemia cancer cell line with $\mathrm{IC}_{50}$ value on the micromolar level. Azulene scaffold also creates perspective applications for diabetes treatment. To sum up, many structures that contain azulene moiety can be considered as candidates for drugs. Nevertheless, more research in the area of toxicity needs to be carried out before moving to clinical trials and the market.

Acknowledgements This work has been supported by the National Science Centre, Poland, through grant No. 2015/19/N/NZ7/01342.

\section{Compliance with ethical standards}

Conflict of interest The authors declare that they have no conflict of interest.

Publisher's note Springer Nature remains neutral with regard to jurisdictional claims in published maps and institutional affiliations. 
Open Access This article is licensed under a Creative Commons Attribution 4.0 International License, which permits use, sharing, adaptation, distribution and reproduction in any medium or format, as long as you give appropriate credit to the original author(s) and the source, provide a link to the Creative Commons license, and indicate if changes were made. The images or other third party material in this article are included in the article's Creative Commons license, unless indicated otherwise in a credit line to the material. If material is not included in the article's Creative Commons license and your intended use is not permitted by statutory regulation or exceeds the permitted use, you will need to obtain permission directly from the copyright holder. To view a copy of this license, visit http://creativecommons. org/licenses/by/4.0/.

\section{References}

1. Bar-El Dadon S, Reifen R. Vitamin A and the epigenome. Crit Rev Food Sci Nutr. 2017;57:2404-11. https://doi.org/10.1080/ 10408398.2015.1060940

2. Saari JC. Vitamin A and vision. In: Asson-Batres MA, RochetteEgly C, (Eds). The biochemistry of retinoid signaling II. Dordrecht, the Netherlands: Springer; 2016. p. 231-59.

3. Huang Z, Liu Y, Qi G, et al. Role of vitamin A in the immune system. J Clin Med. 2018;7:258 https://doi.org/10.3390/jcm7090258

4. Cañete A, Cano E, Muñoz-Chápuli R, Carmona R. Role of vitamin A/retinoic acid in regulation of embryonic and adult hematopoiesis. Nutrients 2017;9:159 https://doi.org/10.3390/nu9020159

5. Moutinho M, Nunes MJ, Rodrigues E. The mevalonate pathway in neurons: it's not just about cholesterol. Exp Cell Res. 2017;360:55-60. https://doi.org/10.1016/j.yexcr.2017.02.034

6. Cheng HM, Koutsidis G, Lodge JK, et al. Tomato and lycopene supplementation and cardiovascular risk factors: a systematic review and meta-analysis. Atherosclerosis. 2017;257:100-8. https://doi.org/10.1016/j.atherosclerosis.2017.01.009

7. Alakurtti S, Mäkelä T, Koskimies S, Yli-Kauhaluoma J. Pharmacological properties of the ubiquitous natural product betulin. Eur J Pharm Sci. 2006;29:1-13. https://doi.org/10.1016/j.ejps.2006.04.006

8. Amiri S, Dastghaib S, Ahmadi M, et al. Betulin and its derivatives as novel compounds with different pharmacological effects. Biotechnol Adv. 2020;38:107409 https://doi.org/10.1016/j.biotecha dv.2019.06.008

9. Schwiebs A, Radeke HH. Immunopharmacological activity of betulin in inflammation-associated carcinogenesis. Anticancer Agents Med Chem. 2018;18:645-51. https://doi.org/10.2174/ 1871520617666171012124820

10. Zhang D-M, Xu H-G, Wang L, et al. Betulinic acid and its derivatives as potential antitumor agents. Med Res Rev. 2015;35:1127-55. https://doi.org/10.1002/med.21353

11. Tang J-J, Li J-G, Qi W, et al. Inhibition of SREBP by a small molecule, betulin, improves hyperlipidemia and insulin resistance and reduces atherosclerotic plaques. Cell Metab. 2011;13:44-56. https://doi.org/10.1016/j.cmet.2010.12.004

12. Jiang $\mathrm{Q}, \mathrm{Wu} \mathrm{Y}$, Zhang $\mathrm{H}$, et al. Development of essential oils as skin permeation enhancers: penetration enhancement effect and mechanism of action. Pharm Biol. 2017;55:1592-1600. https:// doi.org/10.1080/13880209.2017.1312464

13. Xie F, Chai J, Hu Q, et al. Transdermal permeation of drugs with differing lipophilicity: effect of penetration enhancer camphor. Int J Pharm. 2016;507:90-101. https://doi.org/10.1016/j.ijpharm. 2016.05.004

14. Mlala S, Oyedeji AO, Gondwe M, Oyedeji OO. Ursolic acid and its derivatives as bioactive agents. Molecules. 2019;24:2751 https://doi.org/10.3390/molecules24152751
15. Žiberna L, Šamec D, Mocan A, et al. Oleanolic acid alters multiple cell signaling pathways: implication in cancer prevention and therapy. Int J Mol Sci. 2017;18:643 https://doi.org/10.3390/ ijms 18030643

16. Kingston DGI. Taxol, a molecule for all seasons. Chem Commun. 2001; 867-80. https://doi.org/10.1039/b100070p.

17. Andersen FA. Final report on the safety assessment of azulene. Int J Toxicol. 1999;18:27-32. https://doi.org/10.1177/10915818990 1800304

18. Matěnová M, Lorelei Horhoiu V, Dang F-X, et al. Energy transfer in aggregates of bacteriochlorophyll c self-assembled with azulene derivatives. Phys Chem Chem Phys. 2014;16:16755-64. https:// doi.org/10.1039/C4CP01311E

19. Achatz J, Fischer C, Salbeck J, Daub J Functionalized photochromics for molecular switching: the multistabilities of a dihydroazulene-anthraquinone system. J Chem Soc Chem Commun. 1991;504-7. https://doi.org/10.1039/C39910000504.

20. Buica G-O, Lazar I-G, Birzan L, et al. Azuleneethylenediaminetetraacetic acid: a versatile molecule for colorimetric and electrochemical sensors for metal ions. Electrochim Acta. 2018;263:382-90. https://doi.org/10.1016/j.electacta.2018. 01.059

21. Zieliński T, Kędziorek M, Jurczak J. The azulene moiety as a chromogenic building block for anion receptors. Tetrahedron Lett. 2005;46:6231-4. https://doi.org/10.1016/j.tetlet.2005.07.061

22. Dong J-X, Zhang H-L. Azulene-based organic functional molecules for optoelectronics. Chin Chem Lett. 2016;27:1097-104. https://doi.org/10.1016/j.cclet.2016.05.005

23. Xin $\mathrm{H}, \mathrm{Ge} \mathrm{C}$, Jiao X, et al. Incorporation of 2,6-connected azulene units into the backbone of conjugated polymers: towards highperformance organic optoelectronic. Mater Angew Chem Int Ed. 2018;57:1322-6. https://doi.org/10.1002/anie.201711802

24. Cowper P, Pockett A, Kociok-Köhn G, et al. Azulene-thiophene - cyanoacrylic acid dyes with donor- $\pi$-acceptor structures. Synthesis, characterisation and evaluation in dye-sensitized solar cells. Tetrahedron 2018;74:2775-86. https://doi.org/10.1016/j.tet. 2018.04.043

25. Nishimura H, Ishida N, Shimazaki A, et al. Hole-transporting materials with a two-dimensionally expanded $\pi$-system around an azulene core for efficient perovskite solar cells. J Am Chem Soc. 2015;137:15656-9. https://doi.org/10.1021/jacs.5b11008

26. Zargaran A, Borhani-Haghighi A, Salehi-Marzijarani M, et al. Evaluation of the effect of topical chamomile (Matricaria chamomilla L.) oleogel as pain relief in migraine without aura: a randomized, double-blind, placebo-controlled, crossover study. Neurol Sci. 2018;39:1345-53. https://doi.org/10.1007/s10072018-3415-1

27. Gunes T, Akin MA, Sarici D, et al. Guaiazulene: a new treatment option for recalcitrant diaper dermatitis in NICU patients. J Matern Fetal Neonatal Med. 2013;26:197-200. https://doi.org/10. 3109/14767058.2012.722711

28. Leino TO, Turku A, Yli-Kauhaluoma J, et al. Azulene-based compounds for targeting orexin receptors. Eur J Med Chem. 2018;157:88-100. https://doi.org/10.1016/j.ejmech.2018.07.040

29. Pawełczyk A, Sowa-Kasprzak K, Olender D, Zaprutko L. Molecular consortia-various structural and synthetic concepts for more effective therapeutics synthesis. Int J Mol Sci. 2018;19:1104 https://doi.org/10.3390/ijms19041104

30. Hutchings MI, Truman AW, Wilkinson B. Antibiotics: past, present and future. Curr Opin Microbiol. 2019;51:72-80. https:// doi.org/10.1016/j.mib.2019.10.008

31. Yang Y, Peng F, Wang R, et al. The deadly coronaviruses: the 2003 SARS pandemic and the 2020 novel coronavirus epidemic in China. J Autoimmun. 2020;109:102434 https://doi.org/10. 1016/j.jaut.2020.102434 
32. Chiang H-M, Yin J-J, Xia Q, et al. Photoirradiation of azulene and guaiazulene-formation of reactive oxygen species and induction of lipid peroxidation. J Photochem Photobio A: Chem. 2010;211:123-8. https://doi.org/10.1016/j.jphotochem.2010.02.007

33. Damrongrungruang $\mathrm{T}$, Kitchindaopat $\mathrm{N}$, Thanasothon $\mathrm{P}$, et al. Effects of photodynamic therapy with azulene on peripheral blood mononuclear cell viability and singlet oxygen formation. Photodiagnosis Photodyn Ther. 2018;24:318-23. https://doi.org/10. 1016/j.pdpdt.2018.10.015

34. Hayek RRA, Araújo NS, Gioso MA, et al. Comparative study between the effects of photodynamic therapy and conventional therapy on microbial reduction in ligature-induced peri-implantitis in dogs. J Periodontol. 2005;76:1275-81. https://doi.org/10.1902/ jop.2005.76.8.1275

35. Nagai Y, Suzuki A, Katsuragi H, Shinkai K. Effect of antimicrobial photodynamic therapy (aPDT) on the sterilization of infected dentin in vitro. Odontology. 2018;106:154-61. https:// doi.org/10.1007/s10266-017-0321-6

36. Peet J, Selyutina A, Bredihhin A. Antiretroviral (HIV-1) activity of azulene derivatives. Bioorg Med Chem. 2016;24:1653-7. https://doi.org/10.1016/j.bmc.2016.02.038

37. Murafuji T, Kitagawa K, Yoshimatsu D, et al. Heterocyclic bismuth carboxylates based on a diphenyl sulfone scaffold: synthesis and antifungal activity against Saccharomyces cerevisiae. Eur $\mathbf{J}$ Med Chem. 2013;63:531-5. https://doi.org/10.1016/j.ejmech. 2013.02.036

38. Duchesne E, Dufresne SS, Dumont NA. Impact of inflammation and anti-inflammatory modalities on skeletal muscle healing: from fundamental research to the clinic. Phys Ther. 2017;97:807-17. https://doi.org/10.1093/ptj/pzx056

39. Srivastava JK, Pandey M, Gupta S. Chamomile, a novel and selective COX-2 inhibitor with anti-inflammatory activity. Life Sci. 2009;85:663-9. https://doi.org/10.1016/j.lfs.2009.09.007

40. Ma D, He J, He D. Chamazulene reverses osteoarthritic inflammation through regulation of matrix metalloproteinases (MMPs) and NF-k $\beta$ pathway in in-vitro and in-vivo models. Biosci Biotechnol Biochem. 2020;84:402-10. https://doi.org/10.1080/ 09168451.2019.1682511

41. Nihei S, Sato J, Komatsu H, et al. The efficacy of sodium azulene sulfonate L-glutamine for managing chemotherapy-induced oral mucositis in cancer patients: a prospective comparative study. $\mathrm{J}$ Pharm Health Care Sci. 2018;4:20 https://doi.org/10.1186/ s40780-018-0114-2

42. Ma S, Zhang D, Lou H, et al. Evaluation of the anti-inflammatory activities of tanshinones isolated from Salvia miltiorrhiza var. alba roots in THP-1 macrophages. J Ethnopharmacol. 2016;188:193-9. https://doi.org/10.1016/j.jep.2016.05.018.

43. Yokota M, Uchibori $\mathrm{S}$, Hayashi $\mathrm{H}$, et al. Azulene derivatives as TXA2/PGH2 receptor antagonists-II. Synthesis and biological activity of 6-mono- and 6-dihydroxylated-isopropylazulenes. Bioorg Med Chem. 1996;4:575-91. https://doi.org/10.1016/09680896(96)00038-7

44. Ozimec Landek I, Pešić D, Merćep M, et al. Synthesis and antiinflammatory activity of $8 \mathrm{H}-1$-thia-8-aza-dibenzo[e,h]azulenes. J Heterocycl Chem. 2011;48:856-63. https://doi.org/10.1002/jhet.605

45. Ozimec Landek I, Pešić D, Novak P, et al. 2,8-Dithia-dibenzo[e,h] azulenes and their 8-oxa analogs. synthesis and anti-inflammatory activity. Heterocycles. 2009;78:2489-507. https://doi.org/10. 3987/COM-09-11755

46. Najm WI. Peptic Ulcer Disease. Prim Care Clin Pr. 2011;38:383-94. https://doi.org/10.1016/j.pop.2011.05.001

47. NIH National Center of Advancing Translational Sciences. Egualen sodium. 2020. https://drugs.ncats.io/substance/3368L0W034. Accessed 20 Dec 2020.
48. Yanagisawa T, Kosakai K, Izawa C, et al. Synthesis and antipeptic activity of compounds related to the metabolites of sodium 3-ethyl-7-isopropyl-1-azulenesulfonate (KT1-32). Chem Pharm Bull. 1991;39:2429-32. https://doi.org/10.1248/cpb.39.2429

49. Fujio K, Kobayashi H, Ozeki S, Fujimori K.Synthesis, characterization, and antipeptic activity of a novel surfactant having an azulene moiety.Chem Lett. 2006;35:1272-3. https://doi.org/10. 1246/cl.2006.1272.

50. Zhang L-Y, Yang F, Shi W-Q, et al. Synthesis and antigastric ulcer activity of novel 5-isoproyl-3,8-dimethylazulene derivatives. Bioorg Med Chem Lett. 2011;21:5722-5. https://doi.org/10.1016/ j.bmcl.2011.08.018

51. Cao T, Li Y, Yang Z, et al. Synthesis and biological evaluation of 3,8-dimethyl-5-isopropylazulene derivatives as anti-gastric ulcer agent. Chem Biol Drug Des. 2016;88:264-71. https://doi.org/10. 1111/cbdd. 12753

52. NIH National Cancer Institute. Cancer statistics. 2020. https://www.cancer.gov/about-cancer/understanding/statistics. Accessed 20 Dec 2020.

53. Phutim-Mangkhalthon A, Teerakapong A, Tippayawat $\mathrm{P}$, et al. Anti-inflammatory effect of photodynamic therapy using guaiazulene and red lasers on peripheral blood mononuclear cells. Photodiagnosis Photodyn Ther. 2020;31:101747 https://doi.org/ 10.1016/j.pdpdt.2020.101747

54. Russo A, Bruno M, Avola R, et al. Chamazulene-rich artemisia arborescens essential oils affect the cell growth of human melanoma cells. Plants. 2020;9:1000 https://doi.org/10.3390/plants9081000

55. Capuzzo A, Occhipinti A, Maffei ME. Antioxidant and radical scavenging activities of chamazulene. Nat Prod Res. 2014;28:2321-3. https://doi.org/10.1080/14786419.2014.931393

56. Uehara $\mathrm{M}$, Minemura $\mathrm{H}$, Ohno $\mathrm{T}$, et al. In vitro antitumor activity of alkylaminoguaiazulenes. Vivo. 2018;32:541-7. https://doi.org/ 10.21873/invivo. 11273

57. Teratani M, Nakamura S, Sakagami H, et al. Antitumor effects and tumor-specificity of guaiazulene-3-carboxylate derivatives against oral squamous cell carcinoma in vitro. Anticancer Res. 2020;40:4885-94. https://doi.org/10.21873/anticanres.14491

58. Hong B-C, Jiang Y-F, Kumar ES. Microwave-assisted [6+4]cycloaddition of fulvenes and $\alpha$-pyrones to azulene-indoles: facile syntheses of novel antineoplastic agents. Bioorg Med Chem Lett. 2001;11:1981-4. https://doi.org/10.1016/S0960-894X(01)00349-3

59. Chen $\mathrm{C}-\mathrm{H}$, Lee O, Yao C-N, et al. Novel azulene-based derivatives as potent multi-receptor tyrosine kinase inhibitors. Bioorg Med Chem Lett. 2010;20:6129-32. https://doi.org/10.1016/j. bmcl.2010.08.025

60. CDC/National Center for Health Statistics. Diabetes. 2020. https://www.cdc.gov/nchs/fastats/diabetes.htm. Accessed 20 Dec 2020.

61. Ikegai K, Imamura M, Suzuki T. et al. Synthesis and biological evaluation of C-glucosides with azulene rings as selective SGLT2 inhibitors for the treatment of type 2 diabetes mellitus: discovery of YM543. Bioorg Med Chem. 2013;21:3934-48. https://doi.org/ 10.1016/j.bmc.2013.03.067.

62. Löber S, Hübner H, Buschauer A, et al. Novel azulene derivatives for the treatment of erectile dysfunction. Bioorg Med Chem Lett. 2012;22:7151-54. https://doi.org/10.1016/j.bmcl.2012.09.064

63. Turku A, Leino TO, Karhu L, Yli-Kauhaluoma J, Kukkonen JP, Wallén EAA, et al. Structure-activity relationships of 1-benzoylazulenes at the $\mathrm{OX}_{1}$ and $\mathrm{OX}_{2}$ orexin receptors. ChemMedChem. 2019;14:965-81. https://doi.org/10.1002/cmdc.201900074

64. Luo Q, Yang Z-L, Yan Y-M, Cheng Y-X, Ganotheaecolin A. A neurotrophic conjugated ergosterol with a naphtho[1,8-ef]azulene scaffold from Ganoderma theaecolum. Org Lett. 2017;19:718-21. https://doi.org/10.1021/acs.orglett.7b00012 